\title{
UM EXERCÍCIO RIGOROSO DE INVESTIGAÇÃO CLÍNICA
}

\author{
Angélica Bastos
}

\begin{abstract}
Resumo
O artigo visa extrair da produção psicanalitica de Juan Carlos Cosentino as coordenadas de sua investigação. Com base no procedimento segundo o qual Freud concebeu a elaboração do saber em psicanálise, busca-se delimitar suas questões clínicas. Nas fobias, na angústia e nos sonhos, o psicanalista distingue duas ordens de laço na experiência analítica: por um lado, a fantasia e a neurose de transferência, e, por outro, a estrutura. Procura-se demonstrar o quanto sua releitura de Freud é movida por problemáticas originais, configurando uma pesquisa rigorosa impulsionada pela direção do tratamento e ditada pela função do desejo do analista.
\end{abstract}

Palavras-chave: Pesquisa em psicanálise. Juan Carlos Cosentino. Fobia. Angústia.

\section{A RIGOROUS EXERCISE ON CLINICAL INVESTIGATION}

\begin{abstract}
The article aims at drawing out the coordinates of investigation from the psychoanalytical production of Juan Carlos Cosentino. Based on the proceedings which Freud conceived knowledge elaboration in psychoanalysis, the clinical questions are delimited in his investigation. The psychoanalyst distinguishes two bond types in the analytical experience in relation to phobias, angst and dreams: on one hand, fantasy and transfer neurosis and on the other hand, the structure. We try to demonstrate how much his reading on Freud is powered by original problems, thus outlining a rigorous research triggered by the treatment course and ruled by the function of the therapist's desire.
\end{abstract}

Keywords: Research in psychoanalysis. Juan Carlos Cosentino. Psychoanalytical clinics. Phobia. Angst.

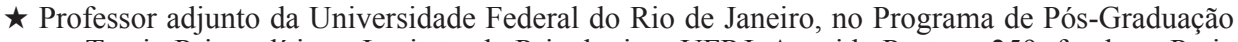
em Teoria Psicanalítica - Instituto de Psicologia - UFRJ. Avenida Pasteur, 259, fundos - Praia Vermelha - Rio de Janeiro, RJ - Brasil. 22290-240. Tels.: UFRJ: 3873-5343 e 38735344.

E-mail: abastosg@terra.com.br 


\section{INTRODUÇÃO}

O trabalho de Juan Carlos Cosentino mostra que na criação do laço psicanalítico há um corte a ser reiterado em cada tratamento, o que faz da clínica o campo de uma experiência que não se confunde com a experiência imediata nem com o experimento científico, mas que se presta a um exercício rigoroso de investigação. O objetivo do presente artigo é detectar os princípios e as coordenadas que orientam sua produção.

Juan Carlos Cosentino é um psicanalista há muito conhecido no Brasil. Autor de livros publicados na Argentina e difundidos aqui, organizador de uma coletânea de artigos no Brasil, autor de artigos editados em livros e periódicos brasileiros, ${ }^{1}$ ele tem participado pessoalmente da transmissão da psicanálise em missões de trabalho entre nós, seja nas universidades, ${ }^{2}$ seja em instituições de psicanálise.

Diante do mal-estar subjetivo, Freud assumiu uma posição ativa que resultou na criação de um dispositivo clínico inusitado e solidário à invenção do inconsciente. Assim, pelo ato de Freud, surgiu a psicanálise em descontinuidade com o que era até então possível pensar, desejar e, sobretudo, fazer.

O modo segundo o qual a investigação psicanalítica se arquiteta já indica uma série de exigências. Segundo Freud, o termo psicanálise comporta três acepções; em primeiro lugar, designa "um procedimento para a investigação de processos mentais que são quase inacessíveis por qualquer outro modo" (FREUD, 1923/1966, p. 287). Numa segunda acepção, a psicanálise é tratamento baseado nessa investigação. Por último, "é uma coleção de informações psicológicas obtidas ao longo dessas linhas, e que gradualmente se acumula numa nova disciplina científica" (FREUD, 1923/1966, p. 287). Essas três acepções se conjugam e se interpenetram, posto que as linhas de investigação e de tratamento estão na base da teoria psicanalítica que só existe à medida que pesquisa e clínica para ela confluem.

A experiência psicanalítica não é mediada por idéias ou conceitos abstratos e mesmo o conceito fundamental (Grundbegriff) não está na base (não é um conceito básico), mas no topo (Cf. FREUD, 1914/1999), como resultado de uma elaboração.

Na base encontra-se o trabalho do inconsciente, trabalho sob transferência, cuja sustentação depende, como apontou Lacan, do desejo do analista. Para conceituar a clínica e transmitir a psicanálise, o analista se remete à experiência inaugural de Freud e dirige indagações a seus textos.

\section{UM PRINCÍPIO DE LEITURA E DUAS ORDENS DE LAÇO}

Ao ler a obra de Freud, Cosentino (1993, 1999a, 2004) não se limita a tratar seu pensamento como um fato; por isso, não recai numa história da ciência ou das idéias. Tampouco toma o fato da obra freudiana para tratá-lo como idéia, não realizando, por conseguinte, uma epistemologia de seus conceitos. Para além da 
história do pensamento e da epistemologia, além do fato e das idéias freudianas, com a psicanálise inaugura-se um novo campo de experiência, irredutível a uma Weltanschauung filosófica ou ao campo do experimento científico. Nem concepção totalizante do mundo, nem investigação de um campo objetivável segundo um modelo de ciência exata, a psicanálise se define por uma práxis e o objeto da teoria psicanalítica coincide com o campo desta práxis. Trata-se do campo de uma experiência mediada pela linguagem, mais especificamente mediada pela transferência, condição da clínica psicanalítica. O rigor na investigação psicanalítica requer a transferência e esta exige do analista que interrogue sua posição.

Sobre o campo da experiência analítica, o trabalho de Cosentino (1998a, 1998 b, 2001, 2004) muito ensina ao leitor que acompanha sua demarcação na descoberta freudiana do inconsciente, pontuada pelas irrupções da dimensão do real, correspondendo ao que Freud circunscreveu como trauma e que hoje, após certos desenvolvimentos teóricos, abordamos como gozo.

Com as primeiras histéricas, Freud se defrontou com o que chamou de contra-vontade, o sujeito impelido a fazer algo apesar de si mesmo ou impedido de fazê-lo, malgrado sua vontade. Se esta pode ser definida como uma faculdade através da qual alguém é capaz de opor-se a si mesmo, de contrapor-se à pressão imperiosa de seus impulsos, a suas idéias intrusivas, descobrimos na contra-vontade a determinação pelo inconsciente e a debilidade da vontade suplantada pela força da pulsão. A compulsão à repetição e a pulsão de morte, a satisfação de outra índole, colocam mais e novas exigências a Freud e aos psicanalistas. Lacan (1962/1998) reabilita o termo vontade e subverte a idéia, introduzindo-o no registro da pulsão de morte e retirando-lhe toda temperança, todo bom-senso, todo bem, com a expressão vontade de gozo.

A investigação de Cosentino (2001) percorre a teorização do campo psicanalítico como campo da linguagem (e do Outro) e seu desdobramento em campo do gozo. Este, à medida que não se deixa absorver na significação do desejo, exige um tratamento, definindo uma clínica do real, que não confunde a dimensão fantasmática com a estrutura em que o sujeito se constitui pela inscrição de uma marca de gozo.

Seu livro Construcción de los conceptos freudianos (COSENTINO, 1993, 1999a) consiste numa leitura conceitual da obra de Freud, uma releitura que acompanha, muito mais que a cronologia, o movimento do pensamento freudiano impulsionado pela problemática clínica. Do fato de que a experiência de Freud nem sempre esteve bem correlacionada à construção teórica, isto é, que a clínica não caminha pari passu com a elaboração conceitual, mas adianta-se a ela, Cosentino $(1993,1999$ a) extrai um princípio de leitura.

Desde os primeiros textos estudados, a partir do núcleo designado por Freud de "patógeno", são formuladas questões que atravessam e estruturam seu trabalho, a saber, a existência de, em primeiro lugar, "Um limite à recordação: o núcleo como um ponto de falta na própria cadeia associativa. Com o dizer, nem tudo pode se dizer" (COSENTINO, 1999a, p. 38) e, em segundo lugar, um limite à significação. Quanto a este, o autor afirma que o núcleo antecipa tam- 
bém o "núcleo genuíno do perigo", assinalado por Freud em Inibição, sintoma e ansiedade (FREUD, 1926/1976). Ele aplica Freud ao próprio texto freudiano e, localiza "um resto que escapa ao dizer, fora da cadeia associativa e da função da palavra. $\mathrm{O}$ que excede a sobredeterminação e introduz com a angústia o registro da causa" (COSENTINO, 1999a, p. 38). Para os psicanalistas, define-se, então, um procedimento de interpretação inconfundível com a hermenêutica que buscaria o desdobramento da significação sempre insaturada e pronta a liberar algo de novo ou ainda não dito. Assim, a linha de investigação do autor segue o que não se deixa capturar pela significação, e que irrompe de modo pontual no fenômeno do estranho e em várias dimensões do horror.

$\mathrm{O}$ autor percorre as obras de Freud e Lacan, endereçando-lhes as questões suscitadas pela distinção de duas ordens de laço na experiência do analista: de um lado, fantasma, frase superegóica, neurose de transferência, aspecto metafórico do sintoma; de outro, os traços de caráter, a estrutura. Na tensão entre esses dois laços que coexistem e se diferenciam, o psicanalista (COSENTINO, 1998b) vai dos estudos das fobias em Freud até ao conceito lacaniano de lalangue (COSENTINO, 2007).

Em relação à servidão, não bastam a tragédia de Édipo, e a neurose de transferência. Há outra dimensão em jogo : a tragédia contemporânea. Ela opera sob transferência, mas não é sintomatizável. Freud a denominou traços de caráter: continuações inalteradas das pulsões originárias ou formações reativas a elas. Traços e formações mais inatingíveis para a análise que o sintoma-metáfora, os processos neuróticos, a neurose de transferência e a dimensão fantasmática ou supereuóica. (COSENTINO, 2001, p. 18)

Inibição, sintoma e angústia foram formas do mal-estar detectadas como respostas ao real, traduzindo a relação do sujeito com o gozo. Da tríade de respostas repertoriadas e teorizadas por Freud, o autor dedica-se intensamente ao estudo da angústia, passando pelas neuroses, especialmente a fobia, e pelos sonhos de angústia que cedo interrogaram o império do princípio do prazer. Em toda incursão que efetua na obra freudiana, ele atende à necessidade de se situar um ponto de exterioridade ao princípio do prazer, ponto que distingue a prática psicanalítica das clínicas que objetivam a dimensão real do mal-estar e neutralizam o sintoma, reduzindo-o ao sofrimento erradicável. O reconhecimento desse ponto exterior à homeostase do prazer permite aos analistas não somente abordar o gozo, enquanto satisfação pulsional além do princípio do prazer, como também apostar no desejo, cuja sustentação requer uma ultrapassagem dos limites do prazer.

A clínica das fobias constitui o terreno privilegiado em que o psicanalista interroga o dispositivo: "as fobias estendem os limites do campo analítico, e por isso, as operações possíveis no marco da transferência, ao não coincidir com a estrutura do fantasma" (COSENTINO, 1998a, p.10). Desde os primeiros artigos de Freud, a reflexão de Cosentino visa estabelecer o estatuto da angústia como afeto e como neurose. Seu minucioso estudo sobre as fobias ressalta o lugar peculiar 
que esta neurose ocupa em relação à histeria e à neurose obsessiva - placa giratória para esses dois tipos clínicos - além do destino que ela dá à angústia. Uma vez que na fobia não se detecta a representação recalcada, a fobia escapa ao "reino da substituição" de uma representação por outra. O autor ressalta momentos em que a abordagem freudiana prefigura uma teorização ulterior, recortando em artigos tidos por pré-psicanalíticos algo que será destacado em Inibição, sintoma e angústia, quando esta assumir um lugar primordial e anterior ao recalque.

Sua trajetória de investigação se prolonga. Em seu comentário sobre Herbert Graf (COSENTINO, 1999b) - o pequeno Hans, cujo caso ele retoma em vários trabalhos - localiza um déficit fantasmático, para o qual o sujeito encontra um sintoma-suplência. Com bases nas fobias graves, enfrenta "o enigmático problema de saber, aquém do fantasmático, de onde vem a neurose, ali onde o sujeito, determinado pela estrutura, se diferencia do fantasma" (COSENTINO, 1998a, p. 10).

Não se trata, no entanto, de uma pesquisa limitada às fobias. Estas conduzem a outras regiões da experiência, como é próprio do inconsciente. Por exemplo, a partir do falo imaginário que acede ao estatuto simbólico de razão do desejo, o psicanalista segue Lacan na afirmação de um resíduo que não pode ser subsumido pelo significante e que, tal como mostram os irracionais, deixa um resto, o objeto $a$, objeto da angústia. Desloca-se, então, da razão à causa do desejo, concernido pela função que cabe a este numa análise.

Por seu caráter incontornável na existência humana, a angústia já se convertera em objeto da filosofia, antes que Freud a situasse no seio da neurose e interrogasse os sonhos de angústia. O foco de seu interesse se concentra, para além do fenômeno da angústia, em seu lugar estrutural, introduzido pela situação traumática de desamparo, que institui a função do objeto. Nessa operação, o psicanalista demarca o "campo da angústia" (COSENTINO $1998 \mathrm{a}$, p. 132) e situa seu objeto, o objeto $a$, no fundamento da divisão constitutiva do sujeito. Daí a angústia ganhar não só o estatuto de lugar e função, mas também o de tempo na constituição do sujeito, uma vez que sua função data de um momento logicamente anterior à cessão desse objeto não objetivável.

A angústia concernia ao campo da linguagem, à medida que se a interrogava do ponto de vista do desejo e do campo do Outro: "a angústia original, o lugar da angústia, se situa no nível do Outro que nada pode fazer com isso que lhe escapa, nada o une a esse grito, já que a cessão do objeto é um entre dois; situa-se entre o Outro e o sujeito" (COSENTINO, 1995, p. 117). A delimitação do campo da angústia culmina em sua releitura no campo do gozo. Conforme Cosentino em sua leitura de RSI (LACAN, 1975-76, seminário inédito), assiste-se a um deslocamento da angústia para o campo do gozo, à medida que ela deixa de ser abordada a partir do desejo do Outro. Assim, ela ultrapassa a dialética entre o sujeito e o Outro para se circunscrever entre os registros e requisitar o reconhecimento do real e do imaginário do corpo no mal-estar.

O ofício do analista o confronta com a necessidade de manejar a angústia que sobrevém no tratamento, de acordo com o que cada um é capaz de suportar. Mas a experiência também indica que ela pode faltar, e que as defesas mobili- 
zadas contra ela arrastam o sujeito no acting-out e na passagem ao ato. Por isso, "Na experiência, é necessário canalizá-la e, se ouso dizer, dosá-la, para não ser por ela submerso. Aí está uma dificuldade correlativa da que há em conjugar o sujeito com o real..." (LACAN, 1964/1979, p. 43).

O psicanalista argentino enfrenta essa dificuldade. Antes de tudo, preocupa-se em afinar o funcionamento do dispositivo com essa dimensão real da experiência do inconsciente. Uma análise não deixa intocado o fantasma, desvela o lugar de objeto que o sujeito ocupava, e abala a identificação com o objeto do fantasma como causa do desejo do Outro. A opacidade do desejo do Outro e as lacunas em seu discurso acionam a angústia e confrontam o sujeito com o fato de que não sabe que objeto ele é para o Outro. Nessa direção, Cosentino localiza uma dimensão de horror no tratamento e interroga os destinos a que está sujeita a neurose de transferência, correlativa ao fantasma.

Sob a temática do despertar, o psicanalista contempla disjunção entre o real e a realidade. Freud vira no sonho o guardião do sono e estabeleceu que se sonha para continuar a dormir. Quando falha a função do sonho e o sonhador acorda, ele mergulha em sua fantasia que vela o real. Lacan assinala no próprio despertar uma função homóloga: a fim de continuar a dormir, ao invés de despertar para o real, o sujeito acorda para a sua realidade de cada dia. O despertar assim entendido desnaturaliza o desejo de dormir. O dispositivo analítico não promove o desejo de dormir. Assim, o desejo do analista opera numa direção que mobiliza a função mediana da angústia entre o gozo e o desejo.

Despertar para o real é impossível porque o encontro com ele é faltoso, isto é, o real se furta ao encontro no instante inapreensível entre o sonho e o despertar.

Mas é impossível despertar: o despertar é o real. Só pode haver nessa borda uma escrita. Resta ainda revisar a construção do dispositivo analítico e a posição do analista, pois o que aí se escreve questiona a "natureza" de sua posição (COSENTINO, 1998a, p. 11).

No terreno dos sonhos, a profundidade da análise de Cosentino (1998a, 2004) não pode ser restituída ao leitor sem o contato direto com seu texto. Ele evidencia que ler Freud não é a mesma coisa que ler qualquer outro autor, porque este inaugurou uma nova maneira de ler: a leitura do inconsciente, na qual os sonhos desempenham papel privilegiado. Essa outra leitura busca uma certa decantação da linguagem, numa pontuação que transgride as normas gramaticais, segundo uma lógica que desdenha a lógica das proposições, tira conclusões de um fragmento de palavra, extrai conseqüências do que se diz nos pedaços de frase, dando ao próprio ato de dizer seu valor máximo. O que não pode ser lido no texto inconsciente, na cadeia associativa, Cosentino encontra nos sonhos que recuperam as marcas de experiências infantis impressionantes. Seus trabalhos recentes (COSENTINO, 2004, 2007) perscrutam no texto freudiano marcas (Eindrücke), impressões, experiências contundentes que ele cuidadosamente distingue dos trilhamentos de traços mnêmicos que se diferenciam uns em relação aos outros. 
De modo original e especialmente bem documentado, ele ensina a ler no texto freudiano as marcas de lalangue e os afetos que ela suscita no sujeito. As marcas de experiências impressionantes correspondem aos depósitos da fala do Outro, detritos do que cada um ouviu antes de poder subjetivar ou significar. Essas escansões e sedimentações dos fragmentos da língua não serão capturadas pela intenção significativa, não ingressarão nos desfiladeiros do significante, e muito menos na comunicação. Tais impressões indeléveis, que ele diferencia dos rastros mnêmicos, são equiparadas ao significante Um, que não é um significante como os demais (COSENTINO, 2004).

\section{Concluindo}

O sintoma especifica o campo psicanalítico e constitui a forma especialmente qualificada para a operação analítica; em sua relação com a linguagem Cosentino (2001) situa o móvel para a investigação psicanalítica. Não basta reformular a teoria e submeter os conceitos à prova da experiência. No retorno da teoria à experiência, cabe ao clínico rever sua prática, fazendo do desejo do analista uma função.

Nós analistas contamos apenas com o sintoma e, além dele, com a linguagem. Questionamos, justamente, a relação entre os dois. O saber atribuído a algo no real não tem nada a ver com o saber que se articula pelo fato de que há um ser que fala. Pois bem, por sua própria condição, procura-se delimitar uma relação entre a perda própria a esse campo - uma dimensão do horror na própria divisão do sujeito - e a função desejo do analista (COSENTINO, 2001, p. 13).

"Eu não procuro; acho" são as palavras de Picasso subscritas por Lacan (1979, p. 14). O efeito de transmissão que o conjunto dos textos de Cosentino são suscetíveis de provocar, deve-se à dimensão de achado presente em sua investigação, guiada não pela busca, mas pelo desejo na experiência do inconsciente. Ao leitor, deixamos o convite para acompanhá-lo em seus achados, dentre os quais salientamos sua refinada leitura da obra de Freud e a concepção de duplo laço da experiência analítica.

\section{Notas}

${ }^{1}$ As referências bibliográficas não pretendem esgotar o conjunto dos artigos do psicanalista disponíveis em língua portuguesa, mas proporcionam uma idéia fidedigna de sua investigação.

2 Vale citar o curso ministrado no Departamento de Psicologia da Universidade Federal Fluminense em 1998 e os acordos CAPES-SECyT entre o Programa de Pós-Graduação em Teoria Psicanalítica da UFRJ e a Universidade de Buenos Aires que vigoraram entre 1999 e 2004. 


\section{REFERÊNCIAS}

COSEnTINO, J. C. Construcción de los conceptos freudianos. Buenos Aires: Manantial, 1993.

A função da angústia. Letra Freudiana (100 anos de Projeto Freudiano), Rio de Janeiro, ano IV, n. 15. p. 101-119, 1995.

Angustia, fobia, despertar. Buenos Aires: Editorial Universitaria de

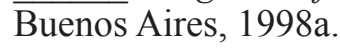

. O primário em Freud: estrutura e fantasma. Ágora - estudos em teoria psicanalítica, Rio de Janeiro, v. 1, n. 1, p. 27-37, 1998b.

. Construcción de los conceptos freudianos I: defensa, sueño, aparato psíquico. Buenos Aires: Manantial, 1999a.

Do pequeno Hans a Herbert Graf. Letra Freudiana: Hans e a fobia, Rio de Janeiro, v. XVII, n. 24, p. 15-17, 1999 b.

. Variações do horror: o destino da neurose. In: $\overline{\text { clínica }}$ psicanalítica. Rio de Janeiro: Contra Capa, 2001. p. 11-20.

O estranho na

. O inconsciente freudiano: as marcas da segunda tópica. Ágora - estudos em teoria psicanalítica, Rio de Janeiro, v. VII, n. 2, p. 235-250, jul./dez. 2004.

. Sueño: discurso y escritura. Revista do Departamento de Psicologia-UFF, Niterói, v. 19, n. 2, p. 297-316, jul./dez. 2007.

FREUD, S. Zur Einführung des Narzissmus (1914). In: Gesammelte Werke. Werke aus den Jahren 1913-1917. Frankfurt am Main: Fischer Verlag, 1999. Bd. X, S. 137-170

Dois verbetes de enciclopédia (1923). In: . Obras Psicológicas Completas de Sigmund Freud. Rio de Janeiro: J. Zahar, 1966. v. XVIII, p. $287-$ 311. Edição Standard Brasileira.

Inibição, sintoma e ansiedade (1926). In: . Obras Psicológicas Completas de Sigmund Freud. Rio de Janeiro: J. Zahar, 1976. v. XX, p. 93-201. Edição Standard Brasileira.

LACAN, J. Kant com Sade (1962). In: 1998. p. 776-803. . Escritos. Rio de Janeiro, Zahar,

O seminário LIVRO 11: Os quatro conceitos fundamentais da Psicanálise (1963-64). Rio de Janeiro: J. Zahar, 1979. . RSI (1975-76) [seminário inédito].

Recebido em: novembro de 2006 Aceito em: abril de 2007 